\title{
Carbon Nanotube Synthesis by Arc Discharge in Water Using Metal Cathodes*
}

\author{
Takio Kizu ${ }^{\dagger}$ Shinya Aikawa, and Eiichi Nishikawa \\ Department of Electrical Engineering, Tokyo University of Science, \\ 1-14-6 Kudankita, Chiyoda-ku, Tokyo 102-0073, Japan \\ (Received 10 January 2010; Accepted 22 February 2010; Published 1 May 2010)
}

\begin{abstract}
Carbon nanotube (CNT) synthesis by arc discharge in water can yield high-crystallinity CNTs using simple equipment. However, it is difficult to control the morphology of CNTs, such as their length, diameter, and number of layers, because the mechanism of CNT production by arc discharge method is complicated. We describe how the morphology of CNTs depends on the cathode metal used in arc discharge. When a nickel or tungsten cathode was used, the layer number distribution was narrower than when a graphite electrode was used. Additionally, the peak position of the inner diameter distribution was downshifted in the case of tungsten. The downshift is considered to be caused by the presence of tungsten nanoparticles as a catalyst. [DOI: 10.1380/ejssnt.2010.203]
\end{abstract}

Keywords: Carbon nanotube; Arc discharge; Scanning electron microscopy (SEM); Transmission electron microscopy (TEM); Raman scattering spectroscopy; Thermo gravimetric analysis (TGA); Catalysis

\section{INTRODUCTION}

Carbon nanotubes (CNTs) are distinctive in their mechanical, chemical, and physical properties; hence, they are considered a promising next-generation carbon material. Nanocarbon is synthesized by arc discharge [1], laser ablation, and chemical vapor deposition (CVD). Electrical arc discharge in water is particularly simple and cost-effective because it does not require vacuum devices [2-4]. These factors are important for future application, however, it is difficult to control the morphology of CNTs, such as their length, diameter, and number of layers. Moreover, production of carbon impurities including amorphous carbon and graphite flakes is difficult to suppress during arc discharge.

In almost all the research employing arc discharge in water, CNTs are produced with arc discharge using graphite for both anode and cathode. Here, we present the morphological changes in the produced CNTs, such as the number of layers, when metal is used as the cathode. In this process, we can also obtain multiwalled carbon nanotubes (MWCNTs) having a high-crystallinity graphite layer structure.

\section{EXPERIMENTAL}

Figure 1 shows a schematic diagram of the experimental apparatus. $200 \mathrm{~mL}$ of pure water was prepared in a glass beaker, which was cooled in an ice water bath. Graphite, iron, nickel, and tungsten rods (5-mm diameter) were used as cathodes. A graphite rod and a metal rod, used as the anode and cathode, respectively, were submerged in the glass beaker and then connected to a DC power supply. The voltage between the electrodes and the upper current limit of the power supply were set at $50 \mathrm{~V}$ and $20 \mathrm{~A}$, re-

*This paper was presented at 7th International Symposium on Atomic Level Characterizations for New Materials and Devices, The Westin Maui Resort \& Spa, Hawaii, U.S.A., 6-11 December, 2009.

†Corresponding author: nishilab@rs.kagu.tus.ac.jp

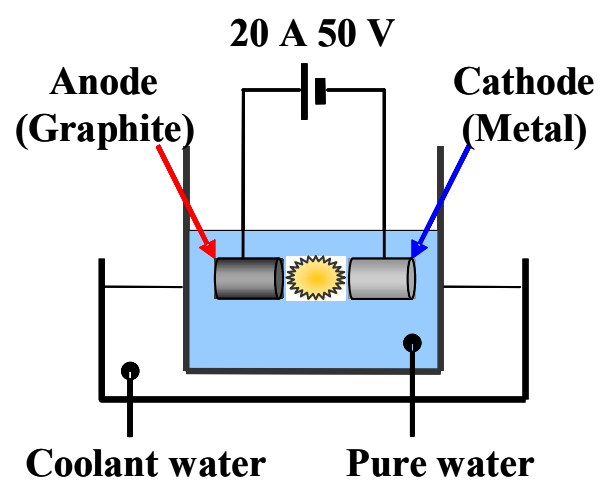

FIG. 1: Schematic diagram of experiment for arc discharge in water.

spectively. The interelectrode gap was kept smaller than $0.5 \mathrm{~mm}$. Discharge was operated for $60 \mathrm{~min}$. Immediately after an arc discharge, carbon soot was generated from the surface of the cathode electrodes, and thus the liquid in the beaker turned black in $60 \mathrm{~min}$. The products in the beaker were filtered using a filter paper. The filtered residues were observed by transmission electron microscope (TEM; Hitachi H-9500, operated at $200 \mathrm{kV}$ ) equipped with an energy-dispersive X-ray spectrometer (EDS) and analyzed with a Raman spectrometer (JASCO NRS-3200, excited by a 532-nm laser). Thermogravimetric analysis (TGA) was performed by a thermogravimetric differential thermal analysis instrument (TG-DTA; SII Nano Technology EXSTAR 6200). The surface of the cathodes was observed by scanning electron microscopy (SEM; Carl Zeiss SUPRA 40, operated at $10 \mathrm{kV}$ ).

\section{RESULTS AND DISCUSSIONS}

Figure 2 shows TEM images of the generated products by the discharge using graphite $(\mathrm{C})$, iron $(\mathrm{Fe})$, nickel $(\mathrm{Ni})$, and tungsten $(\mathrm{W})$ as the cathode. In the case of $\mathrm{C}, \mathrm{Ni}$, or $\mathrm{W}$, high-crystallinity MWCNTs were obtained; in other words, CNTs were not synthesized when Fe was used as the cathode. In this case, the particles that are 

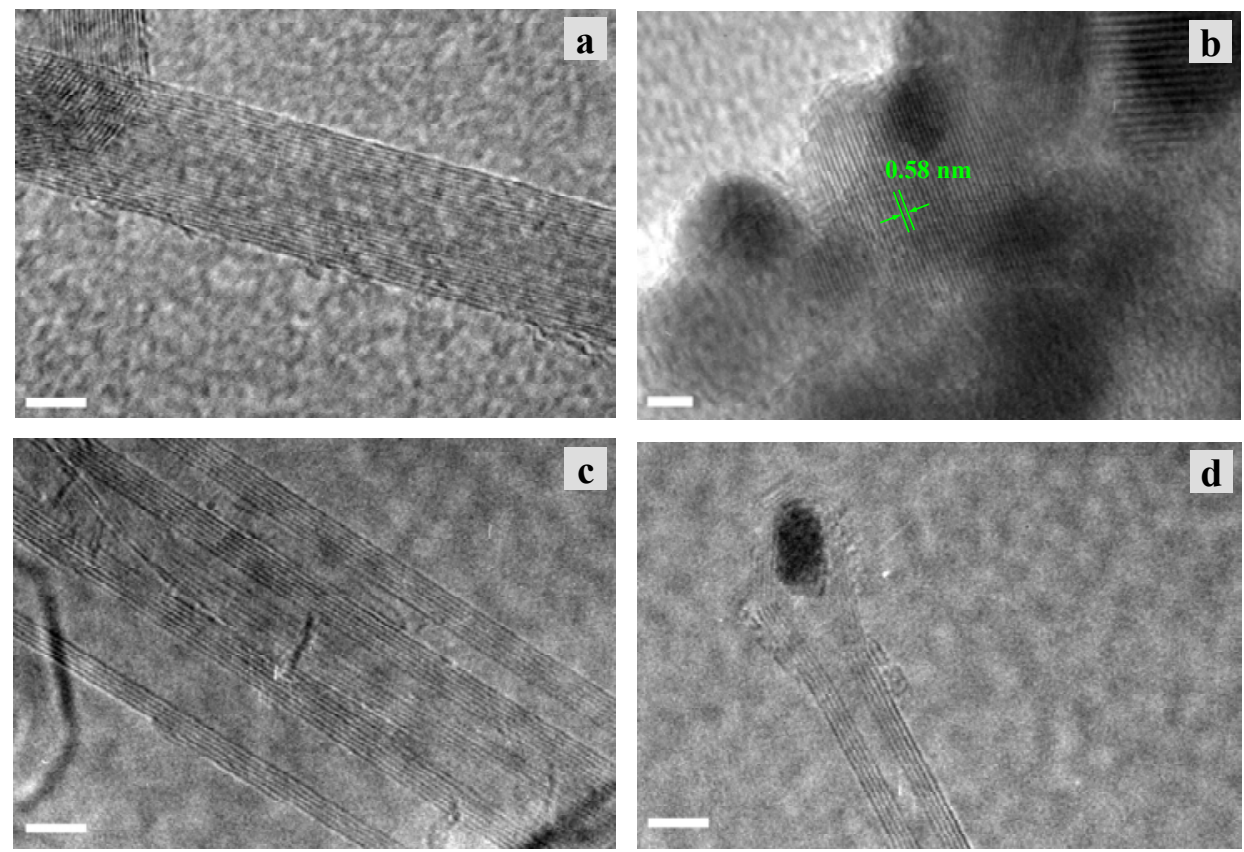

FIG. 2: TEM images of carbon nanotubes synthesized by arc discharge in water using (a) graphite, (c) nickel, and (d) tungsten as the cathode. (b) Iron oxide particle synthesis by arc discharge in water using iron as the cathode. Scale bar in all images is $5 \mathrm{~nm}$.

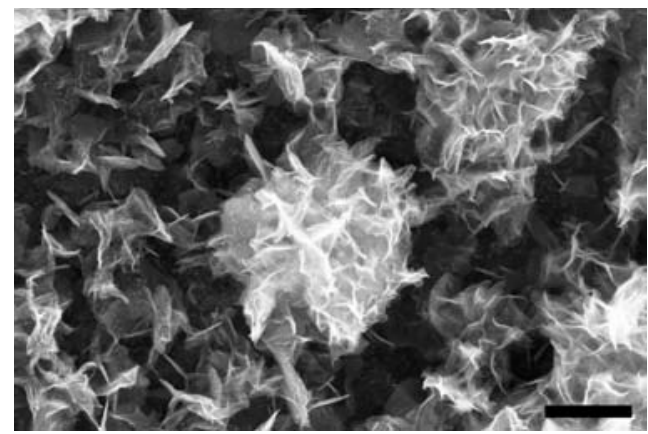

FIG. 3: SEM image of iron oxide particle synthesis by arc discharge in water using iron as the cathode. Scale bar in the image is $500 \mathrm{~nm}$. CNTs cannot be synthesized on the cathode surface.

not graphite particulate as shown in Fig. 2(b) were produced, because the distance between the lattice fringes was approximately $0.58 \mathrm{~nm}$, which is not corresponding to that of graphitic structures. This result together with the Raman spectrum shown in Fig. 5 indicates that they were iron oxide particles. In the case of $\mathrm{W}$, some MWCNTs were grown from the W nanoparticles (black part in Fig. 2(d)). Figure 3 shows SEM image of the Fe cathode surface. This figure also demonstrates that CNTs cannot be synthesized on the Fe cathode surface. It seems that the cathode deposits are carbon nanowall $[5,6]$. However, other analysises are needed to characterize this particle.

Figure 4(a) shows a histogram of the layer number of the CNTs, which was estimated by TEM images. According to the histogram, when $\mathrm{Ni}$ or $\mathrm{W}$ was used as the cathode, the layer number distribution of the synthesized CNTs was narrower than that with a graphite cathode. In
TABLE I: Comparison of the average, minimum, and maximum values of the $G / D$ ratio from the Raman spectrum in the case of $\mathrm{C}, \mathrm{Ni}$, and $\mathrm{W}$.

\begin{tabular}{cccc}
\hline \hline Cathode & \multicolumn{3}{c}{ G/D ratio } \\
Material & Average & Min & Max \\
\hline $\mathrm{C}$ & 2.3 & 1.8 & 3.2 \\
$\mathrm{~W}$ & 3.0 & 1.3 & 6.2 \\
$\mathrm{Ni}$ & 3.4 & 1.8 & 4.3 \\
\hline \hline
\end{tabular}

TABLE II: Ratio by weight of CNTs, $\alpha$-C, graphite flakes, and metals, calculated from TGA results.

\begin{tabular}{ccccc}
\hline \hline $\begin{array}{c}\text { Cathode } \\
\text { Material }\end{array}$ & $\alpha-\mathrm{C}$ & \multicolumn{3}{c}{ Weight ratio (wt \%) } \\
CNTs & $\begin{array}{c}\text { Graphite } \\
\text { flake }\end{array}$ & $\begin{array}{c}\text { Metal } \\
\text { (ash) }\end{array}$ \\
\hline $\mathrm{C}$ & 0 & 80 & 19 & 1 \\
$\mathrm{Ni}$ & 3 & 69 & 1 & 25 \\
$\mathrm{Fe}$ & 0 & 0 & 0 & 100 \\
$\mathrm{~W}$ & 0 & 69 & 15 & 16 \\
\hline \hline
\end{tabular}

addition, the peak position of the distribution was downshifted when $\mathrm{W}$ or $\mathrm{Ni}$ was used as the cathode. In the case of the $\mathrm{W}$ cathode, the downshift and narrowing are considered to be caused by presence of $\mathrm{W}$ nanoparticles as a catalyst. Figure 4(b) shows the distribution of the inner diameter of the CNTs, which was measured using the interlayer distance of graphite $(0.34 \mathrm{~nm})$ in the TEM images. When $\mathrm{Ni}$ or $\mathrm{W}$ was used as the cathode, the inner diameter distribution of the synthesized CNTs was also narrower than that with a graphite cathode.

Figure 5 shows the Raman spectrum of the products 

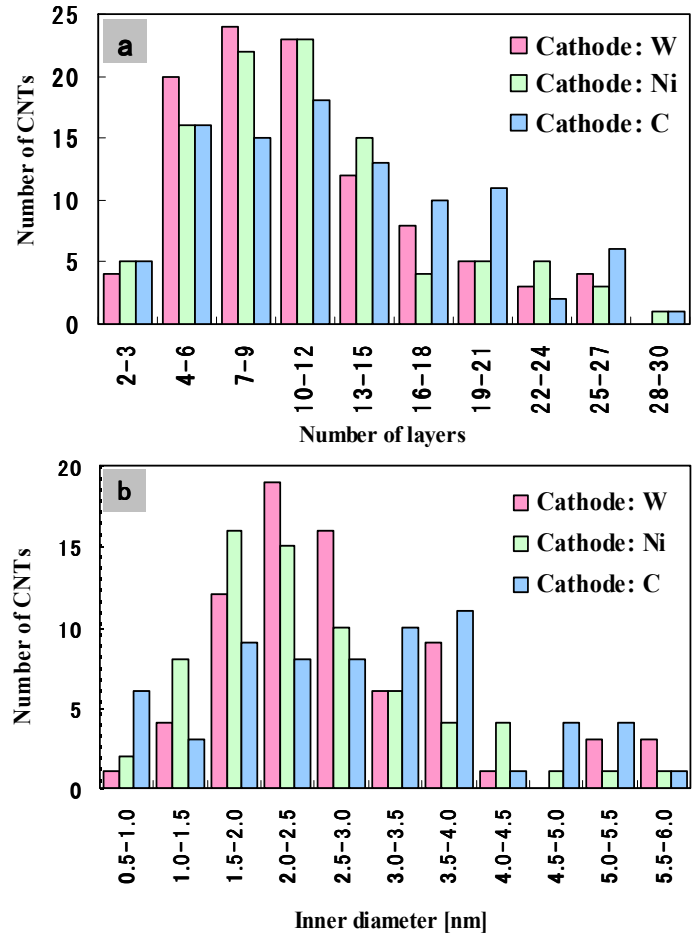

FIG. 4: Histograms of (a) layer number of CNTs and (b) inner diameter of CNTs synthesized by arc discharge in water as estimated by TEM images.

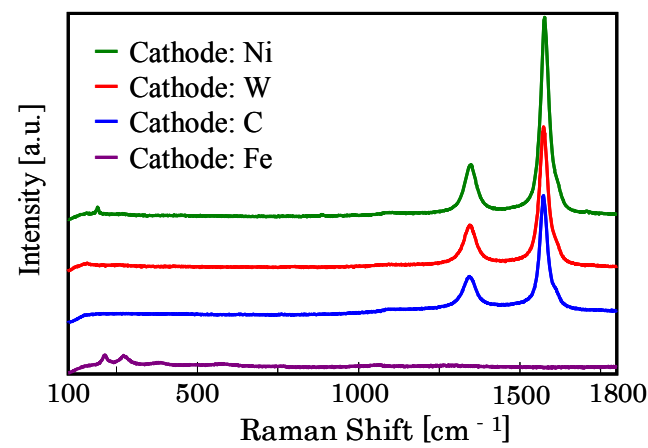

FIG. 5: Raman spectrum of the products when Ni, W, C, or Fe was used as the cathode.

prepared by arc discharge in water with several cathode materials. In this spectrum, G-band $\left(1580 \mathrm{~cm}^{-1}\right)$ and Dband $\left(1340 \mathrm{~cm}^{-1}\right)$ peaks were clearly seen, except for the Fe cathode. We suppose that the spectrum of Fe, placed at the bottom in Fig. 5, is due to $\mathrm{Fe}_{3} \mathrm{O}_{4}$ and $\gamma$-FeOOH [7]. The G-band derives from crystalline graphite; the D-band is related to defects on the nanotubes, graphitic impurities (such as graphite flakes from the graphite electrode), and amorphous carbon $(\alpha-\mathrm{C})[8]$. The ratio of G-band intensity to D-band intensity $(\mathrm{G} / \mathrm{D}$ ratio) can be related to the purity of CNTs. We estimated the purity from the average $\mathrm{G} / \mathrm{D}$ ratio. Table I shows the average, minimum, and maximum G/D ratio with several cathode materials. When Ni was used as the cathode, the product purity was the highest.

Figure 6 shows TGA curves of each as-grown sample with a heating rate of $20^{\circ} \mathrm{C} / \mathrm{min}$ in dry air. The lines

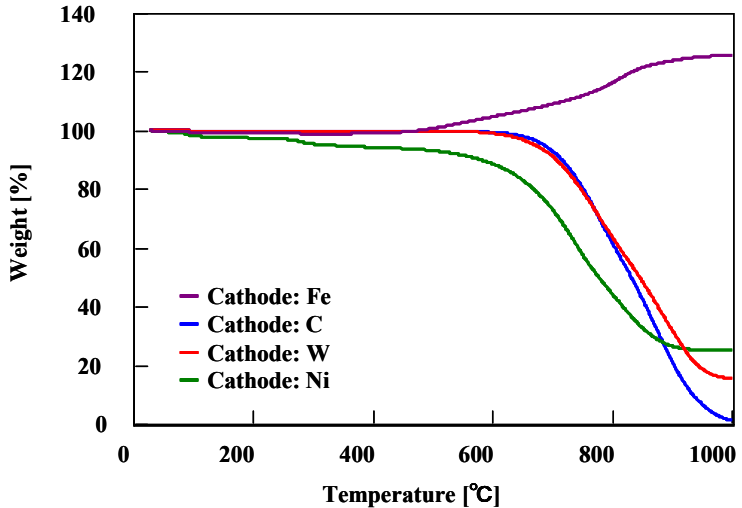

FIG. 6: TGA curve of the filtered residues when Ni, W, C, or Fe was used as the cathode.

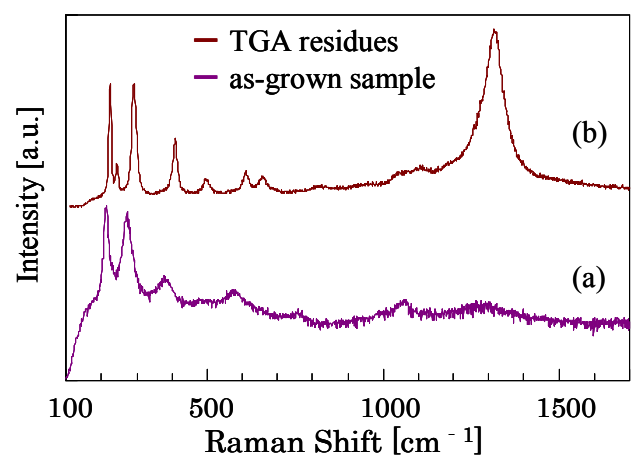

FIG. 7: Raman spectrum of (a) the as-grown sample and (b) the TGA residues when Fe was used as the cathode.

show weight loss as a function of temperature from 30 to $1000^{\circ} \mathrm{C}$. In the case of $\mathrm{C}, \mathrm{Ni}$, and $\mathrm{W}$ cathodes, weight loss was observed at around $350^{\circ} \mathrm{C}$, which corresponds to the combustion temperature of $\alpha-\mathrm{C}$ [8]. The ranges 450 to $850^{\circ} \mathrm{C}$ and 850 to $1000^{\circ} \mathrm{C}$ correspond to the combustion temperatures of MWCNTs and bulky graphite flakes (approximately $15 \mu \mathrm{m}$ in size), respectively. TGA data reveals that the ashed residuals are metal oxide. In the case of the Fe cathode, the sample weight increased from $400^{\circ} \mathrm{C}$. We suppose this was the oxidation of the iron oxide particles which are most likely $\mathrm{Fe}_{3} \mathrm{O}_{4}$ or $\gamma$-FeOOH. Figure 7 shows Raman spectrum of (a) the as-grown sample and (b) the TGA residues by the discharge in water using $\mathrm{Fe}$ as the cathode. The spectrum reveals that the oxidized residues are $\alpha-\mathrm{Fe}_{2} \mathrm{O}_{3}$ [7].

Table II shows the ratio by weight of CNTs, carbonaceous impurities, and metals calculated from the obtained samples. We calculated the mass of CNTs as shown in Table III. In the case of the Ni cathode, the amount of CNTs was the highest compared with other products. We suggest that using $\mathrm{Ni}$ as the cathode can effectively reduce the generation of bulky graphite flakes.

\section{CONCLUSIONS}

We investigated how the morphology of CNTs depends on cathode metals. We found that the layer number dis- 
TABLE III: Amount of sample and calculated mass of CNTs.

\begin{tabular}{ccc}
\hline \hline Cathode & \multicolumn{2}{c}{ Weight } \\
Material & Amount of sample & Mass of CNTs \\
\hline $\mathrm{C}$ & $0.124 \mathrm{~g}$ & $0.119 \mathrm{~g}$ \\
$\mathrm{Ni}$ & $0.203 \mathrm{~g}$ & $0.140 \mathrm{~g}$ \\
$\mathrm{Fe}$ & $1.848 \mathrm{~g}$ & $0 \mathrm{~g}$ \\
$\mathrm{~W}$ & $0.149 \mathrm{~g}$ & $0.102 \mathrm{~g}$ \\
\hline \hline
\end{tabular}

tribution was narrower with a nickel or tungsten cathode than with a graphite cathode. Moreover, the peak position of the diameter distribution was downshifted when using tungsten as the cathode. The downshift is considered to be caused by the presence of tungsten nanoparticles, which catalyze CNT growth. In addition, nickel used as cathode limited the generation of bulky graphite flakes so that pure CNTs were generated. Therefore, this method allows the control of purity and layer number of CNTs using metals as the cathode.
[1] S. Iijima, Nature 354, 56 (1991).

[2] N. Sano, H. Wang, M. Chhowalla, I. Alexandrou, and G. A. J. Amaratunga, Nature 414, 506 (2001).

[3] Y. L. Hsin, K. C. Hwang, F.-R. Chen, and J.-J. Kai, Adv. Mater. 13, 830 (2001).

[4] H. Lange, M. Sioda, A. Huczko, Y. Q. Zhu, H. W. Kroto, and D. R. M. Walton, Carbon 41, 1617 (2003).

[5] Y. Ando, X. Zhao, and M. Ohkohchi, Carbon 35, 153
(1997).

[6] K. Tanaka, M. Yoshimura, A. Okamoto, and K. Ueda, Jpn. J. Appl. Phys. 44, 2074 (2005).

[7] D. L. A. de Faria, S. Venancio, and M. T. de Oliveira, J. Raman Spectrosc. 28, 873 (1997)

[8] M. S. Dresselhaus and P. C. Eklund, Adv. Phys. 49, 705 (2000). 